\title{
High efficiency InGaAs solar cells on Si by InP layer transfer
}

\author{
James M. Zahler \\ Aonex Technologies, Pasadena, California 91106 \\ Katsuaki Tanabe ${ }^{\text {a) }}$ \\ Thomas J. Watson Laboratory of Applied Physics, California Institute of Technology, \\ Pasadena, California 91125 \\ Corinne Ladous and Tom Pinnington \\ Aonex Technologies, Pasadena, California 91106 \\ Frederick D. Newman \\ Emcore Photovoltaics, Albuquerque, New Mexico 87123 \\ Harry A. Atwater ${ }^{\text {b) }}$ \\ Thomas J. Watson Laboratory of Applied Physics, California Institute of Technology, \\ Pasadena, California 91125
}

(Received 29 April 2007; accepted 11 June 2007; published online 3 July 2007)

\begin{abstract}
$\mathrm{InP} / \mathrm{Si}$ substrates were fabricated through wafer bonding and helium-induced exfoliation of InP, and InGaAs solar cells lattice matched to bulk InP were grown on these substrates using metal-organic chemical-vapor deposition. The photovoltaic characteristics of the InGaAs cells fabricated on the wafer-bonded $\mathrm{InP} / \mathrm{Si}$ substrates were comparable to those synthesized on commercially available epiready InP substrates, thus providing a demonstration of wafer-bonded $\mathrm{InP} / \mathrm{Si}$ substrates as an alternative to bulk InP substrates for solar cell applications. (c) 2007 American Institute of Physics.

[DOI: $10.1063 / 1.2753751]$
\end{abstract}

Engineered substrates consisting of thin films of InP on $\mathrm{Si}$ handle substrates (InP/Si substrates) have the potential to significantly increase performance while reducing the cost and weight of compound semiconductor solar cells relative to those fabricated on bulk InP substrates. InGaAs solar cells on InP have superior performance to Ge cells at photon energies greater than $0.7 \mathrm{eV}$. The current record efficiency cell for 1 sun illumination was achieved using an InGaP/GaAs/InGaAs triple-junction cell design with an InGaAs bottom cell. ${ }^{1}$ Thermophotovoltaic cells from the InGaAsP family of III-V materials grown epitaxially on InP substrates would also benefit from such an InP/Si substrate. ${ }^{2}$

Additionally, a proposed four-junction solar cell, fabricated by joining subcells of InGaAs and InGaAsP grown on InP with subcells of GaAs and AlInGaP grown on GaAs through a wafer-bonded interconnect, would enable the independent selection of the subcell band gaps for well developed materials grown on lattice matched substrates. ${ }^{3,4}$ Substitution of InP/Si substrates for bulk InP in the fabrication of such a four-junction solar cell could significantly reduce the substrate cost, as described below.

The direct heteroepitaxial growth of InP thin films on $\mathrm{Si}$ substrates has not produced the low dislocation-density high quality layers required for active $\mathrm{InGaAs} / \mathrm{InP}$ in optoelectronic devices due to the $\sim 8 \%$ lattice mismatch between InP and $\mathrm{Si}^{5}{ }^{5}$ Wafer bonding, on the other hand, is not subject to lattice matching limitations associated with epitaxial growth, and defects caused by the lack of crystallographic registry are isolated to the wafer-bonded interface. Thus, provided the wafer-bonded interface does not play an active role in the operation of the device, the independent materials and de-

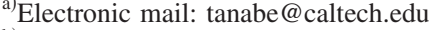

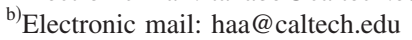

vices fabricated in them can, in principle, have performance typical of devices made on or in the bulk material.

Layer transfer of a high quality single crystal InP film onto a Si bulk substrate can be accomplished through wafer bonding of InP to $\mathrm{Si}$ and exfoliation of a thin film from the InP donor wafer induced by implantation of light elements such as hydrogen and helium, as described in depth in Refs. 6 and 7. Because only a few microns of InP are consumed in the transfer of a film and subsequent reclaim of the InP donor substrate, a single InP wafer could be reused repeatedly to generate many InP/Si substrates, thus reducing the material cost of InP in devices grown on those substrates. In this letter, we describe the fabrication of wafer-bonded $\mathrm{InP} / \mathrm{Si}$ substrates and report the results from the first known demonstration of InGaAs solar cell fabrication on the InP/Si engineered substrates.

InP (001) donor substrates and thermally oxidized $\mathrm{Si}$ (001) handle substrates were used for the fabrication of $\mathrm{InP} / \mathrm{Si}$ substrates for the growth of InGaAs solar cell test structures. The $\mathrm{SiO}_{2}$ film at the bonded interface was found to improve the thermal stability relative to structures fabricated with a direct semiconductor-semiconductor bond. The first step in the InP/Si substrate fabrication was the ion implantation of the InP donor wafer with $\mathrm{He}^{+}$at an energy between 115 and $180 \mathrm{keV}$ to a dose of at least 1.0 $\times 10^{17} \mathrm{~cm}^{-2}$. Prior to wafer bonding, the surfaces of both the $\mathrm{InP}$ donor and the $\mathrm{Si}$ handle substrates were prepared by wet chemical cleaning to remove organic and particulate contaminations, followed by activation of the bonding surfaces with an atmospheric pressure plasma exposure. Bonding between the InP donor and the $\mathrm{Si}$ handle was then initiated at a temperature of $150{ }^{\circ} \mathrm{C}$ or greater. The two substrates were then annealed under uniaxial pressure of at least $1 \mathrm{MPa}$ to promote the formation of covalent bonds between the InP and $\mathrm{Si}$ substrates and induce the exfoliation of a thin layer 

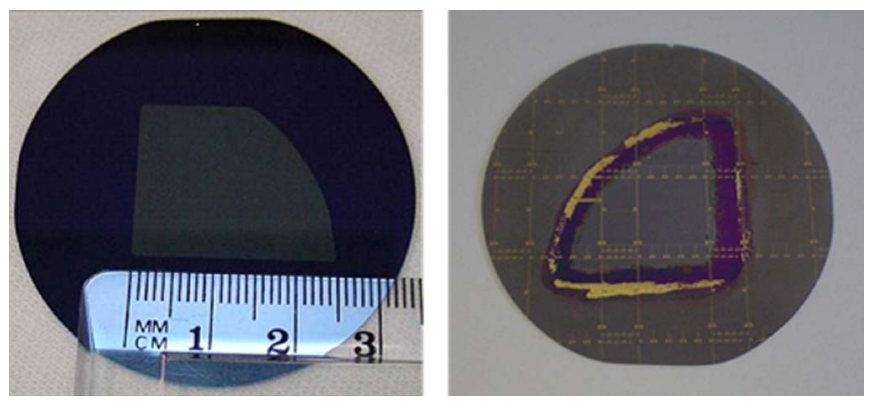

FIG. 1. (Color online) Optical micrographs of (left) a layer-transferred $\mathrm{InP} / \mathrm{Si}$ substrate; one-quarter of a $50 \mathrm{~mm}$ diameter InP layer was transferred onto a $50 \mathrm{~mm}$ diameter Si substrate, and (right) InGaAs solar cells grown on an $\mathrm{InP} / \mathrm{Si}$ substrate.

( $\sim 900 \mathrm{~nm}$ ) of InP thus forming the InP/Si substrate. A typical image of an InP/Si substrate fabricated by transferring a thin $\mathrm{InP}$ film to a $\mathrm{Si}$ substrate with a $\mathrm{SiO}_{2}$ bonding layer is shown in Fig. 1 (left). The film was transferred from an InP substrate implanted with $\mathrm{He}^{+}$to a dose of $1.0 \times 10^{17} \mathrm{~cm}^{-2}$ at an energy of $180 \mathrm{keV}$.

This ion implantation induced exfoliation process results in lattice damage in the transferred film with the peak of that damage roughly coinciding with the exfoliated region. Thus, in the as-transferred $\mathrm{InP} / \mathrm{Si}$ structure, there is a distribution of lattice defects with a peak at the surface of the transferred film decreasing to a minimum defect density in the material adjacent to the bonded interface. Figure 2 shows a representative cross-sectional transmission electron (XTEM) micrograph of a film transferred from InP implanted with $115 \mathrm{keV}$ $\mathrm{He}^{+}$to a dose of $1.0 \times 10^{17} \mathrm{~cm}^{-2}$. The inset selected area diffraction pattern shows that the InP adjacent to the bonded interface is single crystalline. Close inspection of the defect structure using high-resolution XTEM imaging shows that the strain contrast apparent in Fig. 2 is caused both by extended defects that can be directly imaged and point defects such as vacancies and interstitials. For the $\mathrm{InP} / \mathrm{Si}$ substrates used for the growth of InGaAs solar cells, the damaged surface region of the as-transferred InP film was removed, leav-

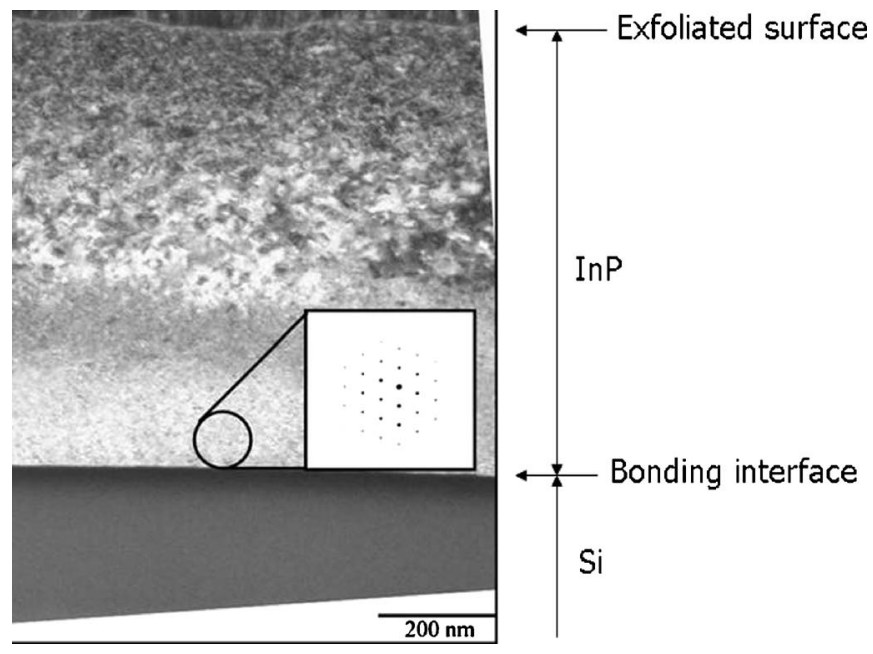

FIG. 2. Cross-sectional transmission electron microscope image of an InP/Si substrate fabricated using InP implanted with $115 \mathrm{keV} \mathrm{He}^{+}$to a dose of $1.0 \times 10^{17} \mathrm{~cm}^{-2}$ showing the strain contrast caused by defects created during ion implantation, and (inset) selected-area diffraction image indicating that the InP adjacent to the bonded interface (within $\sim 200 \mathrm{~nm}$ ) is crystalline.

Downloaded 25 Jul 2007 to 131.215 .225 .175 . Redistribution subject to AIP license or copyright, see http://apl.aip.org/apl/copyright.jsp

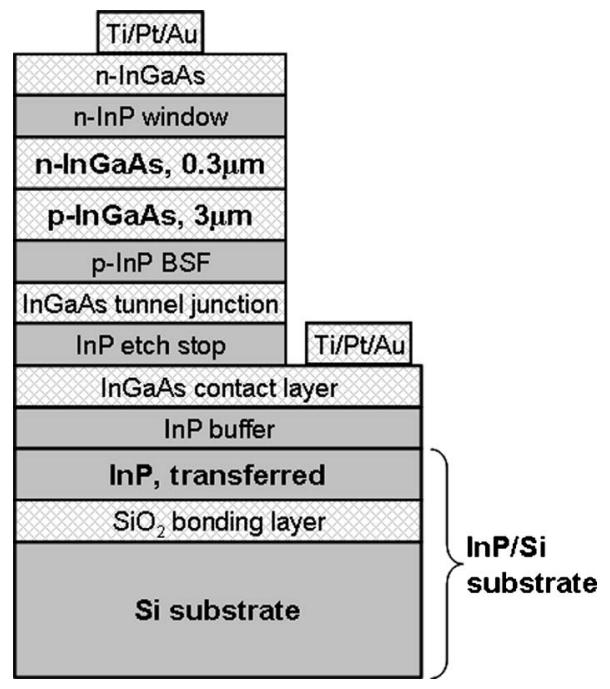

FIG. 3. Schematic cross-sectional view of the InGaAs solar cell grown on the $\mathrm{InP} / \mathrm{Si}$ substrates.

ing a film of $\sim 400 \mathrm{~nm}$ thickness. The transferred InP films were thinned using a combination of inductively coupled plasma reactive ion etching for damage removal and a wet chemical etch for surface smoothing.

To test the performance of III-V compound, active photovoltaic device layers grown on the wafer-bonded $\mathrm{InP} / \mathrm{Si}$ substrates in functional solar cell structures, single-junction InGaAs solar cells were grown both on $\mathrm{InP} / \mathrm{Si}$ substrates and commercial bulk epiready $\mathrm{InP}(001)$ substrates as a reference by metal-organic chemical-vapor deposition. Each of the solar cells had a $n$-type InGaAs emitter and a $p$-type InGaAs base with a band gap energy of $0.74 \mathrm{eV}$, nominally lattice matched to (001) InP. Although we have not investigated the strain in these epitaxial InGaAs layers in detail yet, it is supposed that they are under tensile strain due to the difference in thermal expansion between $\mathrm{InP}$ and $\mathrm{Si}$ from the analysis with a similar heterostructure in Ref. 6. The cells were designed to enable convenient and low-resistance contact to both base and emitter through the top surface of the cell. A schematic of the InGaAs cell structure is shown in Fig. 3. The cell consists of a $1 \mu \mathrm{m}$ thick InP buffer layer doped $n$ type with a target carrier concentration of 1 $\times 10^{19} \mathrm{~cm}^{-3}$ that functions as a current spreading layer for lateral back side contact. Back side and front side contacts were made using $\mathrm{Ti} / \mathrm{Au}$ contacts on an $\mathrm{InGaAs}$ doped $n$ type with a target carrier concentration of $1 \times 10^{19} \mathrm{~cm}^{-3}$. An InGaAs tunnel-junction was used to switch the carrier type from the $p$ type in the base to $n$ type in the back side contact structure, allowing the front and back contacts to be fabricated with a single lithographic process. The remainder of the structure was typical of a single-junction InGaAs cell. No antireflective coating was used in the fabrication of the test cells. A typical image of the InGaAs solar cells grown on the $\mathrm{InP} / \mathrm{Si}$ substrate is shown in Fig. 1 (right).

Light current-voltage $(I-V)$ characteristics of the $4 \mathrm{~mm}^{2}$ InGaAs cells grown on the InP/Si templates and on bulk InP (001) substrates were measured under AM1.5 Global illumination truncated at $850 \mathrm{~nm}$ by a long-pass filter, to mimic the optical configuration of subcells under a GaAs cell. The resulting $I-V$ data are shown in Fig. 4 . The device parameters for the InGaAs cell grown on the wafer-bonded InP/Si substrate were $J_{\mathrm{sc}}=24.9 \mathrm{~mA} \mathrm{~cm}-2, V_{\mathrm{oc}}=0.30 \mathrm{~V}$, and $\mathrm{FF}=0.66$, 


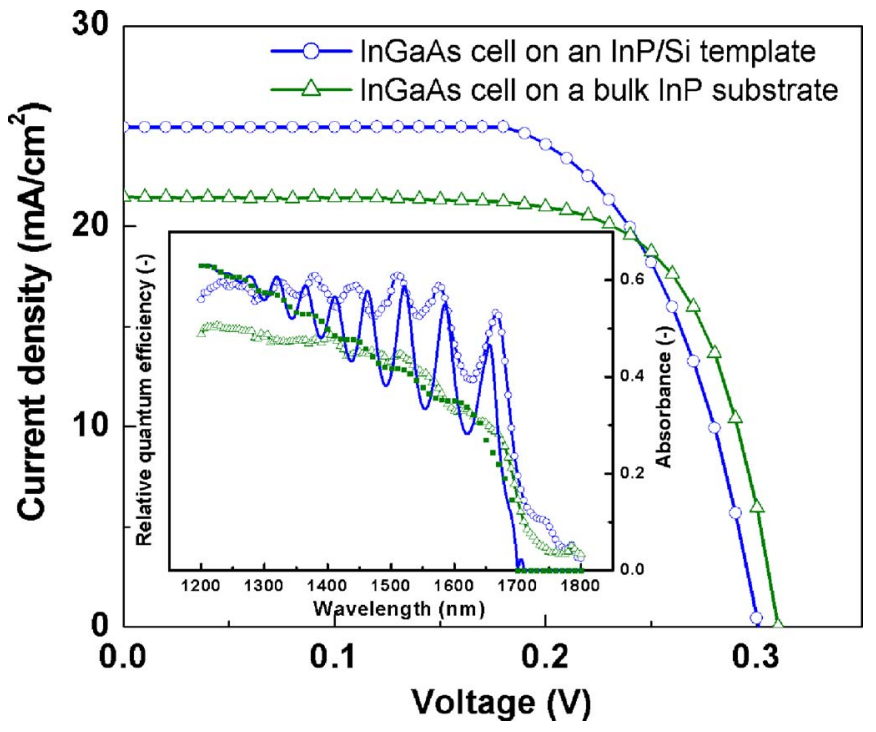

FIG. 4. (Color online) Light $I-V$ curves and (inset) spectral responses for the InGaAs solar cells grown on an $\mathrm{InP} / \mathrm{Si}$ substrate and on a commercial epiready InP substrate. The $I-V$ measurements were performed under AM1.5G illumination truncated at $850 \mathrm{~nm}$. The calculated absorbances for $\mathrm{InGaAs} / \mathrm{InP} / \mathrm{SiO}_{2} / \mathrm{Si}$ (solid line) and $\mathrm{InGaAs} / \mathrm{InP}$ (dot line) structures are also plotted in the inset.

where $J_{\mathrm{sc}}, V_{\mathrm{oc}}$, and FF are short-circuit current, open-circuit voltage, and fill factor, respectively. This performance corresponds to an energy conversion efficiency of $13.6 \%$ based on the irradiation power density of $36.3 \mathrm{~mW} / \mathrm{cm}^{2}$ for the AM1.5 Global illumination truncated at $850 \mathrm{~nm}$. This performance was comparable to that of the InGaAs cells grown on bulk InP (001) substrates, $J_{\mathrm{sc}}=21.5 \mathrm{~mA} \mathrm{~cm}^{-2}, V_{\mathrm{oc}}=0.31 \mathrm{~V}$, and $\mathrm{FF}=0.70$. Figure 4 (inset) shows the spectral responses for the InGaAs solar cells grown on the InP/Si substrate and a bulk InP substrate. The larger $J_{\text {sc }}$ and the higher quantum efficiency for the cell grown on the $\mathrm{InP} / \mathrm{Si}$ substrate are attributed to enhanced light trapping effects in the waferbonded cell structure, due primarily to reflection at the bonding interfaces. The reflectivity of the $\mathrm{InP} / \mathrm{SiO}_{2} / \mathrm{Si}$ interface is estimated to be $\sim 0.45$ at maximum in the IR range for normal incidence due to the large refractive index differences at the $\mathrm{InP} / \mathrm{SiO}_{2}$ and $\mathrm{SiO}_{2} / \mathrm{Si}$ interfaces compared to a reflectivity at the InGaAs/InP interface of less than 0.005. Light trapping effects might also be enhanced by the slightly rougher top surface for cells grown on $\mathrm{InP} / \mathrm{Si}$ substrates, attributable to the increased roughness of the $\mathrm{InP} / \mathrm{Si}$ substrate growth surface $(\sim 10 \mathrm{~nm} \mathrm{rms})$, relative to the bulk, epiready InP $(001)$ substrates $(<1 \mathrm{~nm}$ rms $){ }^{8,9}$ The enhanced photocurrent and the oscillatory variation of the spectral quantum efficiency for the InGaAs cell on the $\mathrm{InP} / \mathrm{Si}$ substrate were well modeled by a simple one-dimensional optical calculation of the absorbance of the InGaAs layer in the $\mathrm{InGaAs} / \mathrm{InP} / \mathrm{SiO}_{2} / \mathrm{Si}$ structure relative to the InGaAs/InP reference structure, as shown in the inset of Fig. 4. No significant band gap shift was caused by the $\mathrm{InP} / \mathrm{Si}$ substrate structure, as indicated by the spectral response. These light
$I-V$ characteristics and spectral response results indicate that $\mathrm{InP} / \mathrm{Si}$ substrates are promising alternative substrates to InP bulk wafers for InGaAs solar cell fabrication. The obtained $J_{\text {sc }}$ of $24.9 \mathrm{~mA} \mathrm{~cm}^{-2}$ for the InGaAs cell on the InP/Si substrate is large enough to current match to state-of-the-art InGaP/GaAs two-junction cells. ${ }^{10,11}$ This InGaAs cell is therefore a strong candidate for the bottom cell of an ultrahigh efficiency three-junction cell with its significantly higher $V_{\text {oc }}$ than the conventional Ge bottom cell. ${ }^{12-14}$

In this letter, we demonstrated InGaAs solar cell fabrication on layer-transferred $\mathrm{InP} / \mathrm{Si}$ substrates. Such $\mathrm{InP} / \mathrm{Si}$ substrates could be used as substrates for InGaAsP/InGaAs dual-junction solar cells lattice matched to InP as well as conventional InP single-junction cells. Ultimately, InP/Si substrates are extendable for fabrication of ultrahigh efficiency four-junction AlInGaP/GaAs/InGaAsP/InGaAs cells via a direct bond interconnect between subcell structures of $\mathrm{InGaAsP} / \mathrm{InGaAs}$ grown on $\mathrm{InP} / \mathrm{Si}$ and $\mathrm{AlInGaP} / \mathrm{GaAs}$ grown on $\mathrm{GaAs}$ to form the overall four-junction cell structure.

The authors would like to thank Anna Fontcuberta i Morral of the Walter Schottky Institute for her work in the development of the InP/Si substrate fabrication process. The work at Aonex Technologies was supported by a Small Business Innovation Research (SBIR) awarded and administered by the Air Force Research Laboratory (AFRL). The Caltech portion of this work was supported by the National Renewable Energy Laboratory.

${ }^{1}$ J. F. Geisz, S. R. Kurtz, M. W. Wanlass, J. S. Ward, A. Duda, D. J. Friedman, J. M. Olson, W. E. McMahon, T. E. Moriarty, and J. T. Kiehl, Appl. Phys. Lett., (in press).

${ }^{2}$ M. W. Wanlass, J. S. Ward, K. A. Emery, M. M. Al-Jassim, K. M. Jones, and T. J. Coutts, Sol. Energy Mater. Sol. Cells 41, 405 (1996).

${ }^{3}$ J. M. Zahler, A. Fontcuberta i Morral, C. G. Ahn, H. A. Atwater, M. W. Wanlass, C. Chu, and P. A. Iles, Proceedings of the 29th IEEE Photovoltaic Specialists Conference (IEEE, New York, 2002), p. 45.

${ }^{4}$ K. Tanabe, D. J. Aiken, M. W. Wanlass, A. Fontcuberta i Morral, and H. A. Atwater, Appl. Phys. Lett. 89, 102106 (2006).

${ }^{5}$ M. Sugo, Y. Takanashi, M. M. Al-Jassim, and M. Yamaguchi, J. Appl. Phys. 68, 540 (1990).

${ }^{6}$ A. Fontcuberta i Morral, J. M. Zahler, S. P. Ahrenkiel, M. W. Wanlass, and H. A. Atwater, Appl. Phys. Lett. 83, 5413 (2003).

${ }^{7}$ A. Fontcuberta i Morral, J. M. Zahler, M. J. Griggs, H. A. Atwater, and Y. J. Chabal, Phys. Rev. B 72, 085219 (2005).

${ }^{8}$ E. Yablonovitch and G. D. Cody, IEEE Trans. Electron Devices ED-29, 300 (1982).

${ }^{9}$ J. H. Hu and R. G. Gordon, Sol. Cells 30, 437 (1991).

${ }^{10}$ T. Takamoto, E. Ikeda, H. Kurita, and M. Ohmori, Appl. Phys. Lett. 70, 381 (1997).

${ }^{11}$ D. B. Jackrel, A. Ptak, S. Bank, H. Yuen, M. Wistey, D. J. Friedman, S. R. Kurtz, and J. S. Harris, Proceedings of the IEEE 4th World Conference on Photovoltaic Energy Conversion (IEEE, New York, 2006), p. 783.

${ }^{12}$ D. J. Friedman and J. M. Olson, Prog. Photovoltaics 9, 179 (2001).

${ }^{13}$ J. M. Olson, D. J. Friedman, and S. R. Kurtz, in Handbook of Photovoltaic Science and Engineering, edited by A. Luque and S. Hegedus (Wiley, New York, 2003), p. 359.

${ }^{14}$ R. R. King, R. A. Sherif, G. S. Kinsey, S. R. Kurtz, C. M. Fetzer, K. M. Edmondson, D. C. Law, H. L. Cotal, D. D. Krut, J. H. Ermer, and N. H. Karam, Proceedings of the International Conference on Solar Concentrators for the Generation of Electricity or Hydrogen (NREL, Golden, 2005). 